\title{
IPD3 Controls the Formation of Nitrogen-Fixing Symbiosomes in Pea and Medicago Spp.
}

\author{
Evgenia Ovchinnikova, ${ }^{1,2}$ Etienne-Pascal Journet, ${ }^{3,4}$ Mireille Chabaud, ${ }^{3,4}$ Viviane Cosson, ${ }^{5}$ Pascal \\ Ratet, ${ }^{5}$ Gerard Duc, ${ }^{6}$ Elena Fedorova, ${ }^{1}$ Wei Liu, ${ }^{1}$ Rik Op den Camp, ${ }^{1}$ Vladimir Zhukov, ${ }^{2}$ Igor \\ Tikhonovich, ${ }^{2}$ Alexey Borisov, ${ }^{2}$ Ton Bisseling, ${ }^{1,7}$ and Erik Limpens ${ }^{1}$
}

${ }^{1}$ Department of Molecular Biology, Wageningen University, Droevendaalsesteeg 1, 6708 PB, Wageningen, The Netherlands; ${ }^{2}$ All-Russia Research Institute for Agricultural Microbiology, Laboratory of Genetics of Plant-Microbe Interactions, Podbelsky chaussee 3, 196608, Pushkin 8, St. Petersburg, Russia; ${ }^{3}$ INRA, Laboratoire des Interactions Plantes-Microorganismes (LIPM), UMR441, F-31326 Castanet-Tolosan, France; ${ }^{4}$ CNRS, LIPM, UMR 2594, F-31326 Castanet-Tolosan, France; ${ }^{5}$ Institut des Sciences du Végétal, UPR2355, CNRS, Avenue de la Terrasse, 91198, Gif sur Yvette, France; ${ }^{6}$ Unité Mixte de Recherche en Génétique et Ecophysiologie des Légumineuses, UMR INRA 102, BP 86510, F-21065 Dijon, France; ${ }^{7}$ King Saud University, P.O. BOX 2454, Riyadh 11451, Kingdom of Saudi Arabia

Submitted 25 January 2011. Accepted 28 June 2011.

\begin{abstract}
A successful nitrogen-fixing symbiosis requires the accommodation of rhizobial bacteria as new organelle-like structures, called symbiosomes, inside the cells of their legume hosts. Two legume mutants that are most strongly impaired in their ability to form symbiosomes are sym1/TE7 in Medicago truncatula and sym33 in Pisum sativum. We have cloned both MtSYM1 and PsSYM33 and show that both encode the recently identified interacting protein of DMI3 (IPD3), an ortholog of Lotus japonicus (Lotus) CYCLOPS. IPD3 and CYCLOPS were shown to interact with DMI3/CCaMK, which encodes a calcium- and calmodulin-dependent kinase that is an essential component of the common symbiotic signaling pathway for both rhizobial and mycorrhizal symbioses. Our data reveal a novel, key role for IPD3 in symbiosome formation and development. We show that MtIPD3 participates in but is not essential for infection thread formation and that MtIPD3 also affects DMI3-induced spontaneous nodule formation upstream of cytokinin signaling. Further, MtIPD3 appears to be required for the expression of a nodule-specific remorin, which controls proper infection thread growth and is essential for symbiosome formation.
\end{abstract}

During the Rhizobium spp.-legume symbiosis, Rhizobium bacteria are hosted inside the cells of a newly formed organ, the root nodule. There, they participate in the formation of new transient organelle-like structures, called symbiosomes, where they find the right conditions to fix atmospheric nitrogen. In legumes such as Medicago truncatula (Medicago) and Pisum sativum (pea), symbiosomes consist of individual bacteria that

Corresponding author: E. Limpens; Telephone +31 317 482036; E-mail: erik.limpens@wur.nl

Nucleotide sequence data for the genes used in this article can be found in the GenBank and EMBL data libraries or TIGR Gene Indices under the following accession numbers: MtIPD3, EF117279; PsIPD3, EF569222; MtGAPDH, BT052418; MtHAP2, EF488826; MtNIN, FJ719774; MtDMI3, AY496049; MtCRE1, AC141922/TC109250, MtERN, EF396330, MtEFD, EU251063, MtSYMREM, TC116072, MtFlotillin-2, GU224279, MtFlotillin-4, GU224281, MtRPG, DQ854741, and MtLIN, EU926661.

* The $e$-Xtra logo stands for "electronic extra" and indicates that six supplementary figures are published online. are surrounded by a plant-derived membrane, called the peribacteroid or symbiosome membrane. Identifying the underlying mechanisms to accommodate the bacteria as new, organelle-like structures inside the plant cells is a key question in symbiosis.

Medicago and pea form so-called undetermined nodules that have a persistent meristem, and symbiosome formation continuously occurs in a few cell layers just below this meristem. There, the bacteria, which are transported via tubular structures called infection threads, are taken up into the nodule cells to form symbiosomes (Brewin 2004; Jones et al. 2007). Symbiosome formation begins with the formation of an unwalled infection droplet at the otherwise cell-wall-bound infection thread. From there, the bacteria are individually taken up into the cell via an endocytosis-like process (Jones et al. 2007; Limpens et al. 2009; Verma and Hong 1996; Whitehead and Day 1997). After release from the infection thread, the symbiosomes divide and, subsequently, the symbiosomes terminally differentiate into their nitrogen-fixing form (Maunoury et al. 2010). Due to the activity of the meristem, nodules show a highly ordered zonation containing symbiosomes at subsequent stages of development (Vasse et al. 1990). The zone below the meristem where infection threads invade the cells and symbiosome formation and subsequent differentiation occur is called the infection zone. In the adjacent fixation zone, infected nodule cells contain fully differentiated symbiosomes where nitrogen fixation takes place.

Although symbiosome formation is a crucial step to establish a successful symbiosis in most legumes, the molecular basis of this process is far from understood. Nodule organogenesis and infection thread formation both require the activation of a signaling pathway by rhizobial signal molecules called Nod factors (Oldroyd and Downie 2008). Several recent studies suggest that symbiosome formation is also controlled by this Nod-factor-signaling pathway. All the Nod-factor-signaling genes appear to be expressed in the nodule, especially in the infection zone of the nodule where symbiosome formation takes place (Bersoult et al. 2005; Limpens et al. 2005; Riely et al. 2007). Nodule-specific knock-down of the leucine-rich repeat-containing receptor kinase DMI2 blocks the release of the bacteria from the infection threads (Capoen et al. 2005; Limpens et al. 2005). Signaling by DMI2 is thought to trigger a calcium-spiking response that is 
decoded in the nucleus by a calcium- and calmodulin-dependent kinase, DMI3, which activates specific transcription factors (Lévy et al. 2004; Mitra et al. 2004). Among transcription factors that are strongly upregulated during nodule formation and involved in symbiosome formation are the CCAAT transcription factor HAP2 and the AP2/ERF transcription factor EFD (Combier et al. 2006; Vernié et al. 2008). Knock-down of HAP2 expression causes a block of release of the bacteria from the infection threads (Combier et al. 2006), while EFD is involved in the control of both release and symbiosome differentiation (Vernié et al. 2008). One of the genes that is upregulated during nodule formation and essential for symbiosome formation encodes a recently identified remorin, called SYMREM. This remorin was shown to interact with DMI2 as well as Nod factor receptors, and knock-down of this remorin blocked the release of the bacteria from the infection threads in the nodule (Lefebvre et al. 2010), Both DMI2 and DMI3 are part of a common symbiotic signaling module that is also essential for the establishment of an arbuscular mycorrhizal (AM) symbiosis (Capoen and Oldroyd 2008; Catoira et al. 2000). Recently, an interacting protein of DMI3, called IPD3 in Medicago and CYCLOPS in Lotus japonicus (Lotus), was identified that was shown to be essential for infection thread formation as well as mycorrhizal arbuscule formation in Lotus (Messinese et al. 2007; Yano et al. 2008).

To get additional insight into the mechanism of symbiosome formation and how Nod factor signaling might control this process, we focused on two mutants, syml (TE7) in Medicago and sym33 in pea, that are most strongly impaired at the first step of symbiosome formation (i.e., the release of the bacteria from the infection thread) (Bénaben et al. 1995; Tsyganov et al. 1998; Voroshilova et al. 2009).

Mtsyml (TE7) was reported to make two types of nodules: small nodules (primordia) (type 1) with infection threads arrested at the outer cortical cells of the root or the cortex of the nodule, and elongated nodules (type 2) filled with an extensive network of infection threads with thick cell walls (Bénaben et al. 1995). Occasionally, some release of bacteria was observed in these type 2 nodules but subsequent symbiosome differentiation did not take place and these plant cells underwent early senescence. The lack of (proper) symbiosome formation is accompanied by a lack of endoreduplication in Mtsym 1 nodule cells, which has been postulated to be a prerequisite for symbiosome development (Maunoury et al. 2010). Similar to Mtsym1, pea sym33 also shows impaired invasion of the nodule primordium at early stages (Voroshilova et al. 2009). At later time points, two types of nodule structures are formed: white nodules with an extensive network of "locked" infection threads, with thick cell walls that do not release bacteria, and nodules containing undifferentiated symbiosomes that undergo premature senescence (Tsyganov et al. 1998; Voroshilova et al. 2001, 2009). Both mutants show signs of host defense responses such as extensive deposition of cell wall material on the infection threads and accumulation of polyphenolics. In addition to the nodulation phenotypes, sym33 was also reported to show decreased root colonization by AM fungi, although arbuscules can still be formed (Jacobi et al. 2003a and b).

Here, we describe the cloning of MtSYM1 and PSSYM33 and show that both encode the interacting protein of DMI3 (IPD3). Our data demonstrate that the common symbiotic signaling module in pea and Medicago has been recruited to facilitate symbiosome formation (i.e., the release of the bacteria from the infection threads) as well as subsequent symbiosome development. We propose a model in which IPD3 controls the activity or stability of a DMI3 complex to allow successful symbiosis.

\section{RESULTS}

\section{Cloning of MtSYM1.}

A map-based cloning strategy was undertaken to clone the MtSYM1 gene. A segregating population (99 F2 plants) of a cross between Mtsyml(TE7) and A20 was used to map the location of Mtsyml to the upper arm of chromosome V, between markers 19c21a and CU469(B). Sequence analysis of the corresponding approximately $1-\mathrm{Mb}$ BAC contig (Supplementary Fig. 1) identified several promising $M t S Y M 1$ candidates because they are thought to play a role in the symbiotic signaling pathway. These include HMGR1, an interactor of DMI2 (Kevei et al. 2007), and IPD3, an interactor of DMI3 (Messinese et al. 2007). Sequence analysis of the genomic regions of these candidate genes identified a mutation in MtIPD3: a deletion of $\mathrm{G}$ at position 1,266 in the MtIPD3 mRNA coding sequence resulting in a frame shift and premature stop leading to a truncated protein that lacks the second nuclear localization signal (NLS) and the predicted $\mathrm{C}$-terminal conserved coiled-coil motif (Fig. $1 \mathrm{~A}$ and B; Table 1). To confirm that MtSYM1 encodes MtIPD3, we complemented the mutant using the MtIPD3 open reading frame under the control of its putative promoter $(1-\mathrm{kb}$ region upstream of the start codon). Two weeks after inoculation, pink nitrogen-fixing nodules were formed on IPD3p:MtIPD3transformed Mtsyml roots containing normally developed symbiosomes (Fig. 2A and B). As a control, Mtsyml was transformed with an empty vector, which resulted in only type 1 and type 2 nodules (Fig. 2C). This confirms that MtSYMI encodes MtIPD3. This allele was named Mtsym1-1.

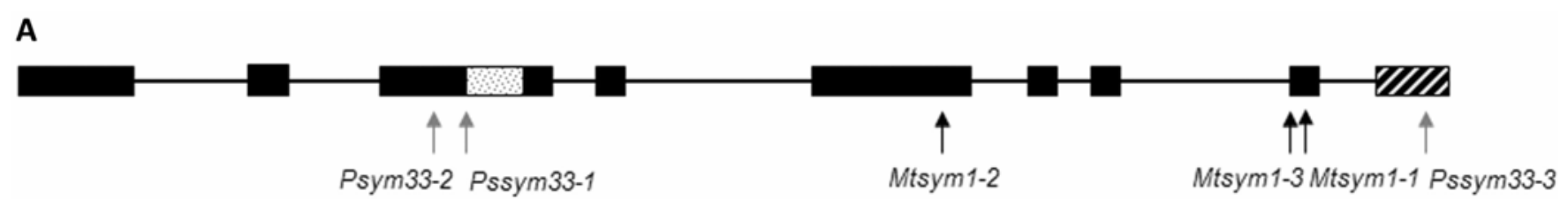

B

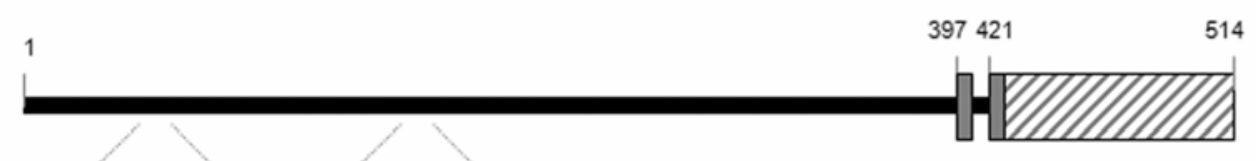

41-tVsQsFRtD $\underline{s} E E L F-54 \quad$ 149-RMTRSR $\underline{s} S L L R R-160$

NLS NLS Coiled-coil domain

Fig. 1. Interacting protein of DMI3 (IPD3) gene and protein structure. A, Schematic representation of the exon-intron structure of the IPD3 gene. Identified mutations in the corresponding Medicago truncatula syml and pea sym33 mutants are indicated. The open box after exon (black rectangles) 3 marks intron 3, which is not spliced in Pssym33-1. B, Schematic representation of the domain structure of IPD3 protein. The conserved C-terminal coiled-coil domain, two identified phosphorylation sites (Grimsrud et al. 2010), as well as two predicted nuclear localization sites (NLS) are indicated. 

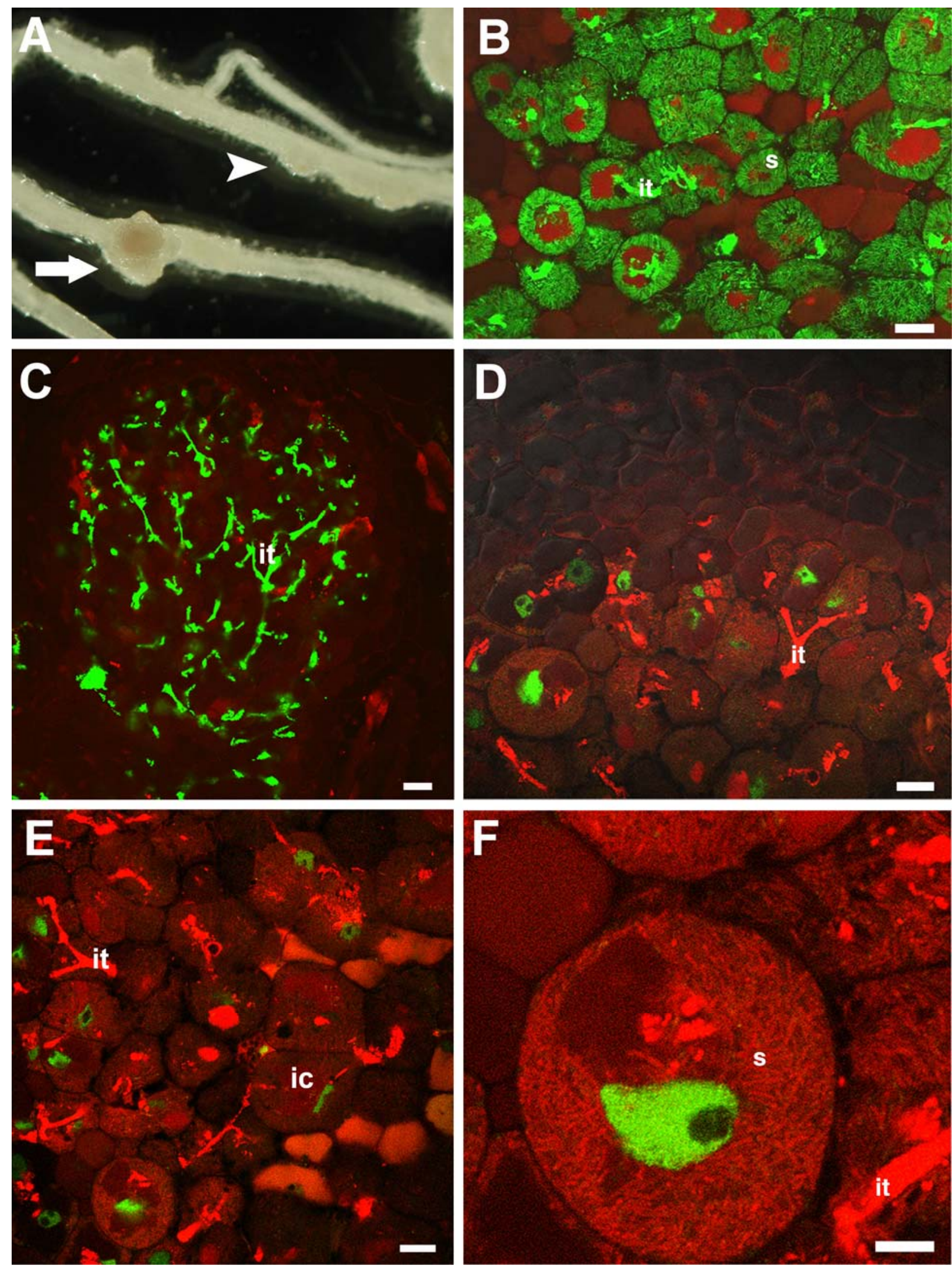

Fig. 2. Complementation of Mtsym1 with MtIPD3. A, Brightfield image of an IPD3p:IPD3 transformed Mtsym1-1 plant, showing a transgenic root (white arrow) with a pink nitrogen-fixing nodule and a nontransgenic root (arrowhead) with white ineffective nodules. B, Confocal image of an IPD3p:IPD3 expressing Mtsym1-1 nodule, showing a wild-type cytology with well developed symbiosomes (s). Rhizobia are expressing green fluorescent protein (GFP). C, Confocal image of a Mtsym1-1 type 2 nodule transformed with an empty vector. Rhizobia are expressing GFP. Note the presence of infection threads in the central tissue of the nodule, but no symbiosomes. D and E, Confocal image of an IPD3p:GFP-IPD3 expressing Mtsym1-1 nodule showing GFP-IPD3 localization in the nucleus of cells in the D, infection zone and $\mathbf{E}$, fixation zone. Rhizobia are expressing mRFP. F, Confocal close-up of GFP-IPD3 localizing to the nucleus of an infected cell in the nodule fixation zone. Note the full complementation of the mutant phenotype, showing well-developed symbiosomes. $\mathrm{S}=$ symbiosome, $\mathrm{It}=$ infection thread. Bars: $\mathrm{B}, \mathrm{D}$, and $\mathrm{E}=20 \mu \mathrm{m} ; \mathrm{C}=50 \mu \mathrm{m} ; \mathrm{F}=10 \mu \mathrm{m}$. 
Additionally, we identified a Tnt1/Mere-transposon tagged line (76A-24), which showed a phenotype comparable with Mtsyml and that segregated as a monogenic recessive trait (data not shown). After two back-crosses (BC), BC2 lines formed both type 1 and type $2 \mathrm{Fix}^{-}$nodules similar to Mtsym 1 (Table 1; data not shown). Crossing 76A-24 to Mtsyml showed that the mutants are allelic. IPD3-Tnt1/Mere transposon junctions in 76A-24 were determined and it turned out that one single copy of Mere1-1 (Rakocevic et al. 2009) is inserted after base 5 of exon 9, resulting in a premature stop (sym1-3) (Table 1). Genotyping of 87 mutant and three wild-type (WT) 76A-24 $\mathrm{BC}$ lines showed that the presence of a homozygous Mere insertion in IPD3 is necessary for the mutant nodulation phenotype (data not shown). Previous allelism tests with Medicago Fix $^{-}$mutants had shown that Mtsyml is allelic to the previously identified complementation group, termed Mtsym 17 (Morandi et al. 2005; Sagan et al. 1998). Mutations in MtIPD3 were confirmed in six Mtsym17 lines by sequencing the IPD3 genomic region (Table 1). TRV15 (sym1-2) contains a 4-bp deletion leading to a frame shift introducing 13 different amino acids and a premature stop, thus deleting 180 amino acids (including both NLS sequences) at the $\mathrm{C}$ terminus. The Mtsym17 mutants TR3, TR9, TR13, TR62, and TR69 all contain the same mutation as Mtsym1-1 (Fig. 1A; Table 1). All Mtsym1 alleles, including back-crossed lines, show a very similar infection and nodulation phenotype forming two types of nodules (Table 1), although the ratio between the two nodule types varied between lines and experiments.

IPD3 is an ortholog of the recently identified CYCLOPS protein from Lotus and is highly conserved in angiosperms that are able to establish an AM symbiosis (Chen et al. 2008; Messinese et al. 2007; Yano et al. 2008). It contains a highly conserved C-terminal coiled-coil domain and a functional NLS. Further, two phosphorylation sites have been identified (Fig. 1B) (Grimsrud et al. 2010; Yano et al. 2008).

\section{Synteny-based cloning of PsSYM33.}

The pea Pssym33 mutants, of which three alleles (RisFixU, SGE-Fix-2, and SGE-Fix-5) have been identified, have a strikingly similar phenotype as Mtsym1: the formation of white nodules with an extensive network of thick-walled infection threads but no release of bacteria (Tsyganov et al. 1998; Voroshilova et al. 2001, 2009). One of the sym33 alleles, SGEFix-2, has been shown to occasionally make pinkish nodules in which bacteria are released but symbiosomes do not develop properly; such nodules are referred to as type 3 nodules (Table 1) (Tsyganov et al. 1998). SGE-Fix-5, as reported for RisFixU (Voroshilova et al. 2001), does not show type 3 nodules but makes mostly type 2 nodules, where release of the bacteria from the infection threads does not occur (Supplementary Fig. 2). SYM33 was mapped to a region on linkage group I in pea, which is highly syntenic with the upper arm of chromosome $\mathrm{V}$ in Medicago (Aubert et al. 2006; Tsyganov et al. 2006). Additional mapping using a cross between WT10584 and SGE-Fix2 (95 F2 plants) positioned SYM33 within a 14-centimorgan region between the markers Gst and Alat-C on pea linkage group I, corresponding to the syntenic location of SYM1 in Medicago (Supplementary Fig. 3). PSIPD3 was converted into a genetic marker and showed complete co-segregation with the mutant phenotype, suggesting that PSSYM33 is the ortholog of MtIPD3. To test this, we sequenced IPD3 from pea in the three available sym33 mutants; RisFixU, SGE-Fix-2, and SGE-Fix5 (Fig. 1A; Table 1). RisFixU (background Finale) showed a mutation in the $5^{\prime}$ splice-site $(\mathrm{G}>\mathrm{A})$ of intron 3. Reverse-transcription polymerase chain reaction (RT-PCR) analysis confirmed that this mutation impairs the splicing of intron 3 (Supplementary Fig. 4), by which a stop codon is introduced leading to a truncated protein of 390 amino acids. SGE-Fix-5 (background SGE) shows a C319T mutation in the PSIPD3 coding sequence, introducing an early stop at amino acid 107. SGE-Fix-2 contains a C1357T mutation causing a premature stop, eliminating the final 60 amino acids. SGE-Fix-5 and RisFixU do not show the occasionally occurring nodules as in SGE-Fix-2, where release of bacteria from the infection threads occurs. This suggests that the phenotype of SGE-Fix-2 may be somewhat leaky, which fits with C-terminal location of the mutation in the protein. Nevertheless, it indicates an important role for the highly conserved 60 amino acids in the C-terminal coiled-coil domain for the function of IPD3. The comparable phenotypes, similar map location, and mutations in PsIPD3 strongly indicate that SYM33 is the ortholog of MtSYM1, and we conclude that PsSYM33 encodes PsIPD3. Together, the data from pea and Medicago reveal a novel, key function for IPD3 in symbiosome formation and development.

\section{IPD3 localizes to the nucleus throughout the nodule infection and fixation zone.}

DMI3 is most strongly expressed in the infection zone of the nodule, where it localizes to the nucleus (Limpens et al. 2005; Smit et al. 2005). Promoter- $\beta$-glucuronidase analyses were reported to show that IPD3 is maximally expressed in the fixation zone of the nodule (Messinese et al. 2007). Significant lower levels were observed in the distal infection zone, where maximal DMI3 expression is observed. To test whether IPD3 localizes to the nucleus in cells of the distal infection zone in which symbiosome formation starts and

Table 1. MtSYM1 and PSSYM33 mutant alleles identified in this study

\begin{tabular}{|c|c|c|c|c|c|c|c|}
\hline \multirow[b]{2}{*}{ Allele } & \multirow[b]{2}{*}{ Original mutant } & \multirow[b]{2}{*}{ Background $^{\mathrm{b}}$} & \multirow[b]{2}{*}{ Reference } & \multicolumn{2}{|l|}{ Mutation } & \multicolumn{2}{|c|}{ Phenotype $^{\mathrm{a}}$} \\
\hline & & & & cDNA & Protein $^{\mathrm{c}}$ & ITs & Nodule \\
\hline sym1-1 & Mtsym1/TE7 & Mt J5 & Bénaben et al. 1995 & Deletion G1266 & +17 aa after K421 & + & 1 and 2 \\
\hline sym1-1 & TR3, TR9, TR13, & & Sagan et al. 1998; & & & & \\
\hline & TR62, TR69 & Mt J5 & Morandi et al. 2005 & Deletion G1266 & +17 aa after K421 & + & 1 and 2 \\
\hline sym 1-2 & TRV15 & Mt J5 & Sagan et al. 1998; & & & & \\
\hline & & & Morandi et al. 2005 & 4-bp deletion from $\mathrm{T} 1000$ & +13 aa after $\mathrm{A} 333$ & + & 1 and 2 \\
\hline sym1-3 & T00076A-24 & $M t$ Jemalong $\mathrm{H} 2 \mathrm{~A}$ & This work & Mere insertion after C1245 & +1 aa after $\mathrm{G} 415$ & + & 1 and 2 \\
\hline sym33-1 & RisFixU & Ps Finale & $\begin{array}{l}\text { Voroshilova et al. } \\
2001\end{array}$ & $5^{\prime}$ splice-site $\mathrm{G}>\mathrm{A}$ mutation intron 3 & +1 aa after I123 & + & 1 and 2 \\
\hline sym33-2 & SGEFix-5 & Ps SGE & This work & $\mathrm{C} 319 \mathrm{~T}$ & Q107 stop & + & 1 and 2 \\
\hline sym33-3 & SGEFix-2 & Ps SGE & Tsyganov et al. 1998 & $\mathrm{C} 1357 \mathrm{~T}$ & R453 stop & + & 2 and 3 \\
\hline
\end{tabular}

${ }^{a}$ IT $=$ infection thread. Nodule $=$ nodule types: type $1=$ small nodules with infection threads limited to the outer cortex, type $2=$ elongated nodules with an extensive network of infection threads but no release of bacteria, and type $3=$ elongated nodules with undifferentiated symbiosomes that undergo premature senescence.

${ }^{\mathrm{b}}$ Genotypic background. $\mathrm{Mt}=$ Medicago truncatula and $\mathrm{Ps}=$ Pisum sativum .

${ }^{\mathrm{c}}$ Abbreviation: $\mathrm{aa}=$ amino acids. 
DMI3 is present, a IPD3p:GFP-IPD3 construct was used to complement Mtsym1-1. Nodules formed on these transgenic roots were pink and showed mature, elongated symbiosomes (Fig. 2F). Green fluorescent protein (GFP)-IPD3 localized to the nucleus of cells throughout the infection zone as well as in the fixation zone (Fig. 2D to F). No or very low signal was observed in the nodule meristem. In contrast to the fulllength IPD3 construct, we were not able to visualize the Mtsym1-1-encoded truncated IPD3 protein fused to GFP. This indicates that the truncated GFP-IPD3 protein is not synthesized or rapidly degraded.

DMI3 was shown to be present throughout the infection zone but not in the cells of the fixation zone that contain mature nitrogen-fixing symbiosomes (Smit et al. 2005). This shows that IPD3 is present in cells that express DMI3 at the time of symbiosome formation and co-localizes with DMI3 in the nucleus. The presence of IPD3 in the fixation zone in the absence of DMI3 suggests that IPD3 has an additional role during these later stages.

\section{IPD3 controls specific genes required for symbiosome formation.}

The presence of IPD3 in the nucleus and the reported interaction with DMI3 (Messinese et al. 2007; Yano et al. 2008) suggest that IPD3 controls the activation of genes that are required for symbiosome formation. Several genes have recently been identified that show DMI3-dependent induction during nodulation and are required for proper infection thread invasion of the nodule primordium or release of the bacteria from the infection threads in the nodule (Marsh et al. 2007). To determine whether some of these genes require a functional IPD3 to be induced in nodules, we compared their expression in WT, type 1, and type 2 Mtsym 1-1 nodules by quantitative RT-PCR. These genes include the coiled-coil protein $R P G$ (Arrighi et al. 2008), the U-box containing E3 ubiquitin-ligase LIN (Kiss et al. 2009), Flotillin-2 and Flotillin-4 (Haney and Long 2010), a nodule-specific remorin SYMREM (Lefebvre et al. 2010), and the transcription factors $E R N$ (Middleton et al. 2007), EFD
(Vernié et al. 2008) and HAP2 (Combier et al. 2006). Mutants of $R P G, L I N$, and $E R N$ show impaired growth of infection threads that fail to penetrate the nodule primordium, comparable with Mtsym1 type 1 nodules (Arrighi et al. 2008; Kiss et al. 2009; Middleton et al. 2007). Mutants of SYMREM and HAP2 show the formation of nodules that are invaded by infection threads but subsequent release of bacteria from the infection threads appears blocked, similar to Mtsyml type 2 nodules (Combier et al. 2006; Lefebvre et al. 2010). Similarly, EFD mutants show delayed release of bacteria and subsequent impaired symbiosome development (Vernié et al. 2008). Flotillin-2 and Flotillin-4 were shown to be required for proper infection thread growth and nodule formation, although the exact nodule phenotype has not yet been described (Haney and Long 2010). Additionally, we examined the expression of $N I N$, an early Nod-factor-induced gene that controls both infection and nodule organogenesis (Marsh et al. 2007).

Type 1 and type 2 nodules were excised from Mtsym1-1 roots 12 days postinoculation (dpi). The use of GFP-expressing rhizobia allowed the selection of type 1 and type 2 nodules based on the penetration of infection threads into the nodules. At 12 dpi, WT nodules formed pink nitrogen-fixing nodules, containing fully developed symbiosomes. NIN, LIN, HAP2, and Flotillin-2 and Flotillin-4 show a more or less similar expression level (less than twofold change) in type 1 and type 2 Mtsym1 nodules compared with WT nodules (Fig. 3). The expression level of ERN was approximately three times higher in Mtsym 1 type 1 and type 2 nodules compared with WT nodules (Fig. 3). RPG showed an approximately eight-times higher expression in Mtsyml type 1 nodules, whereas type 2 nodules showed an expression level comparable with WT nodules (Fig. 3). Therefore, MtIPD3 does not appear to be essential for the induction of these genes. On the other hand, expression of EFD and SYMREM was significantly reduced in Mtsym 1-1 type 1 and type 2 nodules (approximately 7 and $>100$ times, respectively) compared with WT nodules (Fig. 3). This indicates that MtIPD3 is required for the induction of a specific subset of genes that are required for symbiosome formation.

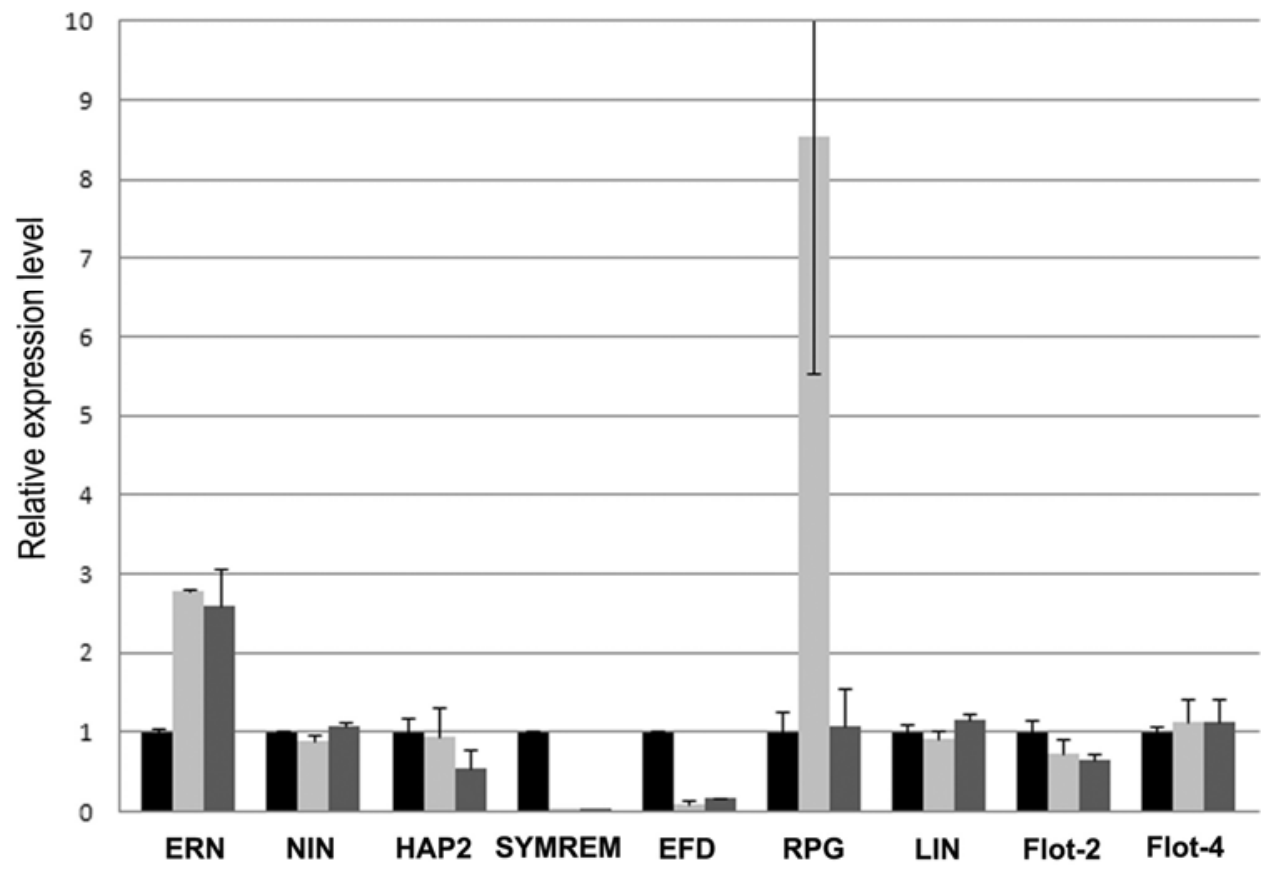

Fig. 3. Quantitative reverse-transcription polymerase chain reaction (qRT-PCR) expression analyses in Mtsym1. qRT-PCR analysis of ERN, NIN, HAP2, SYMREM, EFD, RPG, LIN, and Flotillin2- and -4 in wild-type control $(\mathrm{J} 5)=$ black bars; Mtsym $1-1$ type 1 = light gray bars; and Mtsym $1-1$ type 2 nodules = dark gray bars 12 days postinoculation. The expression level of the corresponding genes in the wild-type control nodules is set to 1 . The relative expression level corresponds to the fold change compared with the wild-type control. 


\section{IPD3 also controls infection thread growth.}

In Lotus, the IPD3 ortholog CYCLOPS was shown to be essential for infection thread formation (Yano et al. 2008). Because DMI3 is required for infection thread formation and, also, SYMREM controls proper infection thread growth (Godfroy et al. 2006; Lefebvre et al. 2010), we reinvestigated whether, in Medicago, IPD3 already affects infection thread formation in the root hairs. In WT control roots, most $(>80 \%)$ infection threads have a tubular structure of one to two rhizobia wide (Fig. 4A; Table 2) (Limpens et al. 2003). In contrast, many infection events in Mtsym 1-1 are blocked at the microcolony stage, forming sac-like structures or infection threads that grow with sac-like structures along their length and abort in the epidermis (Fig. 4B and C; Table 2). This shows that IPD3 also controls infection thread growth already in the root hairs.
Infection thread growth is Nod-factor-structure dependent and likely depends on the activity of Nod-factor-signaling output via DMI3, which might depend on IPD3 (Ardourel et al. 1994; Limpens et al. 2003; Smit et al. 2007). Therefore, we tested whether infection and nodule formation in Mtsyml would be more affected by rhizobia that make aberrant Nod factors. Therefore, we inoculated plants with GFP-expressing $\Delta$ nodL mutant rhizobia, which make aberrant Nod factors that lack an acetate substitution at the non-reducing terminal glucosamine (Ardourel et al. 1994). In WT roots, $\Delta$ nodL rhizobia show impaired infection thread growth in root hairs; most infection threads (approximately 80\%) develop sac-like structures that are nevertheless able to reach and penetrate the primordium and form WT numbers of $\mathrm{N}_{2}$-fixing nodules (Limpens et al. 2003). In contrast, in Mtsym 1-1, the majority of infection events by $\Delta$ nodL mutant rhizobia got arrested at the microcolony stage
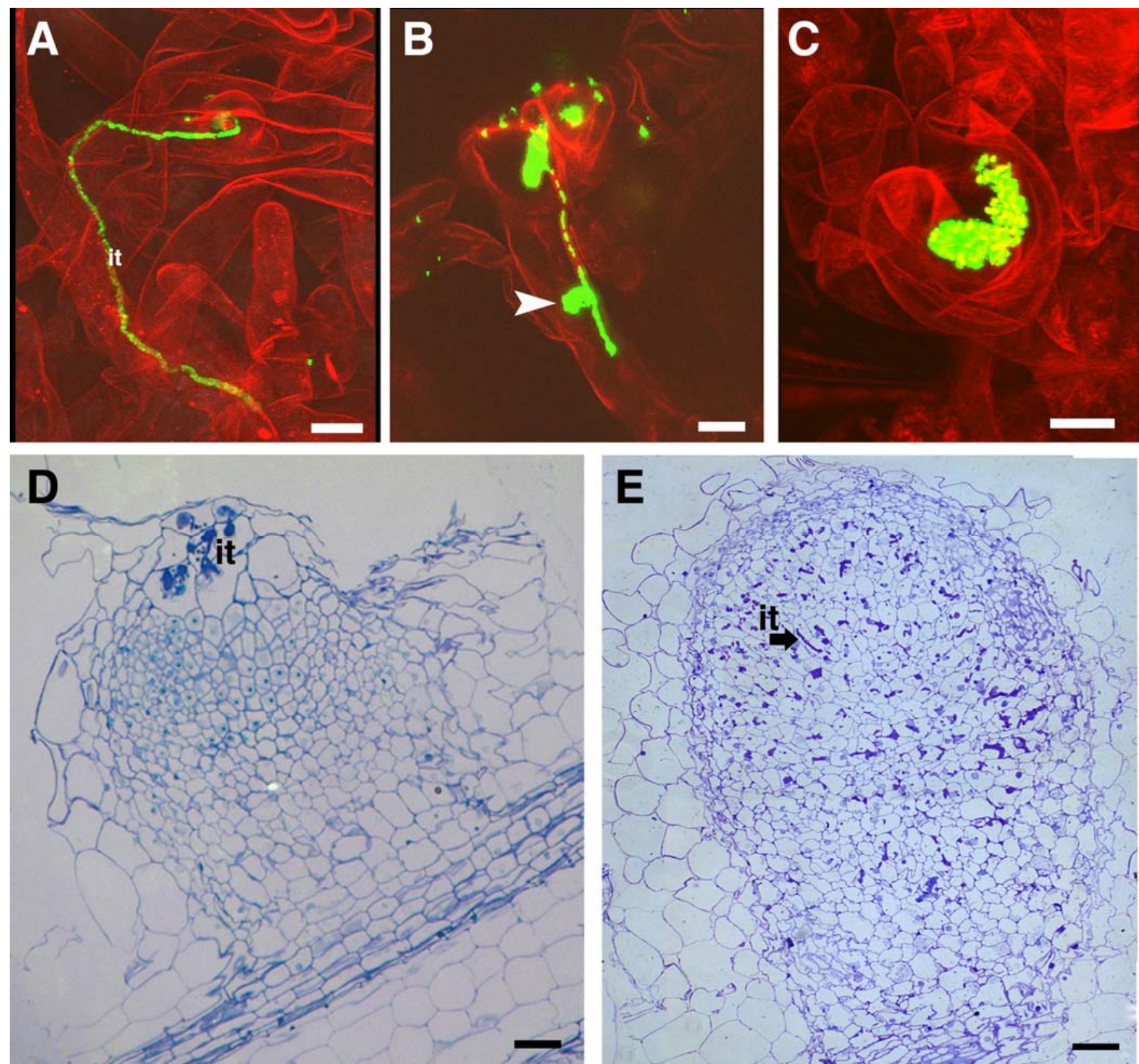

Fig. 4. Mtsym1 infection thread and nodule phenotypes. A, Tubular (wild-type) infection thread in a Mtsym1-1 root hair. B, Infection thread with sac-like structures (arrowhead) along its length in a Mtsym1-1 root hair. C, Sac-like infection arrested at the microcolony stage in a Mtsym 1-1 root hair. Bacteria in A-C are expressing green fluorescent protein. Red color of the root hairs results from autofluorescence. D, Semithin section through a Mtsym 1-1 type 1 nodule. E, Semithin section through a Mtsym1-1 type 2 nodule. It $=$ infection thread. Bars: A to C $=10 \mu \mathrm{m}$; D and E $=100 \mu \mathrm{m}$. 
(Table 2). The infection threads that were formed all contained sac-like structures (Table 2). This resulted in the formation of only type 1 nodules, whereas WT bacteria form approximately 10 to $25 \%$ type 2 nodules (on average, two per root) (Fig. 4D and E; Table 2). Therefore, the infection thread growth defect associated with $\Delta$ nodL rhizobia and in Mtsyml-1 both appear to be exaggerated in this combination, suggesting interference between the two mutant phenotypes.

IPD3 affects DMI3-induced spontaneous nodule formation.

The formation of nodules in Mtsyml indicates that IPD3 is not essential for nodule organogenesis. In contrast, DMI3 is also essential for nodule organogenesis and introduction of an always-active DMI3/CCaMK gene product, lacking the autoinhibitory domain or containing an autophosphorylation-mimick mutation, is sufficient to trigger the formation of spontaneous nodules in the absence of rhizobia (Gleason et al. 2006; Tirichine et al. 2006). Strikingly, when we introduced an always-active DMI3/CCaMK construct lacking the autoinhibitory domain (35S:DMI3*[1-311]) into Mtsym1-1 roots, no spontaneous nodules were formed (0/65 transgenic roots), whereas introduction of $35 S: D M I 3 *$ in WT control roots resulted in the formation of, on average, 5 spontaneous nodules/transgenic root $(n=40)$ (Supplementary Fig. 5A). To rule out secondary effects on spontaneous nodule formation, we made use of a gain-of-function mutation in the cytokinin receptor MtCRE1. A gain-of-function mutation $[\mathrm{L} 266 \mathrm{~F}]$ in the extracellular receiving domain of this receptor histidine kinase also triggers spontaneous nodule formation (Gonzalez-Rizzo et al. 2006; Hayashi et al. 2010; Murray et al. 2007; Tirichine et al. 2007). Introduction of $35 \mathrm{~S}: \mathrm{CRE} 1 *[\mathrm{~L} 267 \mathrm{~F}]$ did trigger the formation of spontaneous nodules on Mtsym1-1 roots (18 spontaneous nodules per 28 roots) with the same efficiency as on WT control roots (16 spontaneous nodules per 20 roots). These data suggest that IPD3 affects the stability or activity of a DMI3 signaling complex upstream of cytokinin signaling.

\section{MtIPD3 is required for efficient mycorrhizal colonization but not arbuscule formation.}

DMI3 is part of the common signaling cascade that is essential for both rhizobial as well as AM symbioses. In Lotus, the IPD3 ortholog CYCLOPS was shown to be essential for arbuscule formation (Yano et al. 2008). However, the pea IPD3 mutant (Pssym33-3, SGE-Fix-2) was reported to show decreased mycorrhizal colonization but with increased arbuscule abundance (Jacobi et al. 2003a and b). Therefore, we examined the AM phenotype in Medicago Mtsym 1-1 according to Trouvelot and associates (1986), using the following parameters: the intensity of AM colonization (M\%) and the arbuscule abundance (a\%) at 18 and 62 dpi. Mtsym1-1 showed decreased AM colonization at 18 dpi (M\%, $P \geq 0.95)$ but increased arbuscule abundance (a\%, $P \geq 0.95$ ) at 62 dpi (Supplementary Fig. 6) similar to the reported AM phenotype of Pssym33-3 (Jacobi et al. 2003a and b). These data suggest that IPD3 is not essential for arbuscule formation in Medicago and pea.

\section{DISCUSSION}

Here, we cloned SYMI from Medicago and SYM33 from pea and show that both encode IPD3. From the phenotypes of the respective mutants, we reveal a novel and essential function for IPD3 in symbiosome formation and development.

One of the striking phenotypes of Mtsyml and Pssym33 is the block of release of rhizobia from the infection threads into the nodule cells. A similar block was found when the essential Nodfactor-signaling protein DMI2 was knocked down specifically in the nodule (Capoen et al. 2005; Limpens et al. 2005) or when a non-legume DMI3 ortholog from rice was introduced into the Medicago dmi3 mutant (Godfroy et al. 2006). The identification of a knock-out mutation in IPD3 now clearly establishes an essential role for the common symbiotic signaling module DMI2DMI3-IPD3 in symbiosome formation. In the orthologous $c y$ clops mutant from Lotus, infection thread formation does not occur by which later roles for CYCLOPS in symbiosome formation could not be observed (Yano et al. 2008).

The presence of IPD3 in the nucleus and its interaction and likely phosphorylation by DMI3 suggest that IPD3 is required to activate specific genes to allow symbiosome formation. By analyzing the expression of a selected set of genes that are induced during nodule formation and required for nodule invasion or symbiosome formation, we show that IPD3 is only essential for a subset of induced genes. Interestingly, the expression of the nodule-specific remorin, SYMREM, was strongly reduced in Mtsyml nodules. Similar to Mtsym1, SYMREM mutants form nodules that are invaded by infection threads but subsequent symbiosome formation does not occur (Lefebvre et al. 2010). Therefore, the impaired expression of SYMREM in Mtsyml can be sufficient to explain the observed Mtsyml phenotypes. Interestingly, this remorin protein interacts with the symbiotic receptors NFP, LYK3, and DMI2 that are essential for perception and signal transduction of rhizobial Nod factors (Lefebvre et al. 2010). IPD3-dependent induction of SYMREM may represent a feedback mechanism to regulate the function of these symbiotic receptors during rhizobial infection. However, the reported presence of SYMREM on mature symbiosomes indicates additional roles for this protein in symbiosome development (Lefebvre et al. 2010). In contrast, the expression of $E R N, R P G, L I N, H A P 2$, and Flotillin-2 and Flotillin-4 does not require MtIPD3 because the expression of these genes in Mtsyml nodules was either comparable with or higher than their expression level in WT nodules 12 dpi (Arrighi et al. 2008; Combier et al. 2006; Haney and Long 2010; Kiss et al. 2009; Middleton et al. 2007; Vernié et al. 2008). The transcription factor ERN and nuclear protein RPG showed an approximately three and eight times higher expression level, respectively, in Mtsyml type 1 (and type 2 in the case of $E R N$ ) nodules compared with the WT, which might

Table 2. Infection thread (IT) and nodule phenotypes of Mtsym1-1 inoculated with different Sinorhizobium meliloti (Sm) 2011 strains $^{\mathrm{a}}$

\begin{tabular}{|c|c|c|c|c|c|c|c|}
\hline \multirow[b]{2}{*}{ Bacterial strain $^{\text {b }}$} & \multirow[b]{2}{*}{ Plant } & \multicolumn{3}{|c|}{ Percent nodule phenotype } & \multicolumn{3}{|c|}{ Percent IT phenotype } \\
\hline & & WT & Type 1 & Type 2 & Sac-like infection ${ }^{\mathrm{c}}$ & IT with sac ${ }^{d}$ & Tubular IT \\
\hline Sm 2011-GFP & WT (J5) & $100(9)$ & & & & $12(3)$ & $88(22)$ \\
\hline Sm 2011-GFP & Mtsym1 & & $75(6)$ & $25(2)$ & $56(35)$ & $40(25)$ & $4(3)$ \\
\hline Sm 2011 $\Delta$ nodL-GFP & WT (J5) & $100(4)$ & ... & $\ldots$ & $12(3)$ & $80(20)$ & $8(2)$ \\
\hline Sm 2011 & Mtsym1 & $\ldots$ & $100(4)$ & $\ldots$ & $81(46)$ & 19 (11) & $\ldots$ \\
\hline
\end{tabular}


reflect a developmental block at early stages of nodule development.

The block in symbiosome formation in Mtsyml and Pssym33 appears to be correlated with the extensive deposition of cell wall material in the infection threads and accumulation of polyphenolic compounds (Bénaben et al. 1995; Tsyganov et al. 1998). This indicates that a more severe defense response is triggered that may block the progression of infection thread growth and release of bacteria. Extensive cell wall depositions were also reported on infection threads in DMI2 knock-down nodules in Sesbania rostrata, where release was blocked (Capoen et al. 2005). The extensive deposition of cell wall material somewhat resembles the formation of cell wall appositions that block the invasion of plant cells by pathogenic fungi during basal defense responses (Schulze-Lefert 2004). Therefore, IPD3 might be required to suppress or control basal defense responses to allow a successful symbiosis.

In addition to release of the bacteria from the infection threads, IPD3 is also required for subsequent symbiosome development. The pea sym33 (SGEFix-2) mutant occasionally forms nodules where release of rhizobia from the infection threads takes place (Tsyganov et al. 1998). Similarly, although we did not observe any release of bacteria from the infection threads in Mtsym 1, it has been reported that occasional release can occur in Mtsyml (Bénaben et al. 1995; Maunoury et al. 2010). In such cases, the symbiosomes remain morphologically undifferentiated and the nodule cells show premature senescence (Tsyganov et al. 1998). A role for IPD3 during later stages of symbiosome development fits with its observed presence in the nucleus of infected cells in the infection zone as well as in the fixation zone. The presence of IPD3 in the fixation zone, where DMI3 is not present, raises the possibility that, in these cells, IPD3 interacts with components other than DMI3 to control late steps of symbiosome development.

IPD3 also controls the progression of infection threads through the root outer cortex and regulates infection thread growth already in the root hairs. Although normal tubular infection threads are formed, a significant number of infection events appear to be blocked at the microcolony stage and form sac-like structures. A more severe block of infection thread formation, as reported for Lotus cyclops mutants (Yano et al. 2008), became apparent when $\Delta$ nodL mutant rhizobia that make different Nod-factor structures (Ardourel et al. 1994) were used to inoculate Mtsym1. Almost all infection threads got arrested at the microcolony stage. This indicates an additive effect of impaired Nod-factor signal input and IPD3dependent signaling in Mtsyml. The less severe effect on infection thread growth observed in Medicago (and pea) compared with Lotus cannot be explained through less severe mutations in IPD3. Mtsym 1-1 shows a mutation nearly identical to that found in the Ljcyclops-5 allele (Yano et al. 2008); the resulting truncated peptide sequence is missing the second NLS and the coiled-coil domain, and it is likely that the protein is unstable or not properly targeted to the nucleus (our data). Moreover, the different alleles show similar phenotypes within each species (Medicago, pea, and Lotus), suggesting they all represent loss-of-function alleles (Table 1). In the accompanying article Horváth and associates (2011) identified a Tnt1 transposon tagged insertion mutant allele of IPD3 in the Medicago 'R108' genetic background. Strikingly, this mutant shows a phenotype comparable with Lotus cyclops, which indicates that the genetic background of the plant ('Jemalong' versus R108) may influence the infection phenotype. Given the fact that, in Medicago, the ratio of type 1 and type 2 nodules is bacterial strain dependent, it is likely that the specific combination of plant and bacteria determines the IPD3 mutant phenotype.
In addition to infection phenotypes, we found that IPD3 is also required for the induction of spontaneous nodules by an always-active truncated DMI3 construct. In Lotus cyclops mutants, an autophosphorylation-mimick always-active form of DMI3 was still able to trigger spontaneous nodules, although the numbers were severely reduced compared with WT plants (Capoen and Oldroyd 2008; Yano et al. 2008). Introduction of an always-active or more sensitive CRE1 cytokinin receptor was able to trigger spontaneous nodules efficiently in Mtsym1, indicating that activation of cytokinin signaling bypasses IPD3 requirement for nodule organogenesis. Similarly, in Lotus, it was recently shown that the action of the cytokinin receptor is downstream of DMI3/CCaMK (Hayashi et al. 2010; Tirichine et al. 2007). DMI3 likely forms a multimeric signaling complex with other proteins in addition to IPD3 that trigger transcriptional responses. Loss of IPD3 could destabilize such a DMI3-dependent protein complex and, thereby, affect DMI3dependent gene expression. Different responses might require different levels of DMI3 complex activity or stability. This model implies that the truncated DMI3 protein forms a complex that is less stable or active than the WT form, and an additional mutation in IPD3 renders this complex unable to trigger spontaneous nodule formation. Such a mechanism could also explain the additive mutant effects observed when inoculating $M t s y m 1$ with $\Delta$ nodL bacteria; the less efficient $\Delta$ nodL Nod factors (lacking the acetate substitution) would activate DMI3 less efficiently in a Mtsyml background that is already reduced for the activity or stability of the DMI3 complex.

IPD3 and DMI3 are widely conserved from monocots to eudicots in plants that are able to establish an AM symbiosis, indicating an ancient role in symbiosis (Messinese et al. 2007; Yano et al. 2008). The rhizobial symbiosis is thought to have recruited part of this mycorrhizal symbiosis pathway (Capoen and Oldroyd 2008; Catoira et al. 2000). The recent identification of a single LysM-type receptor, orthologous to a Nod-factor receptor, in the nonlegume Parasponia sp. that controls the accommodation of both rhizobia and arbuscular mycorrhiza suggests a conserved ancient function for this pathway in the intracellular accommodation of symbionts (Op den Camp et al. 2010). In the pea sym33-3 (SGE-Fix-2) and Medicago sym1-1 mutants, mycorrhizal colonization is decreased; however, arbuscules can still efficiently be formed (Jacobi et al. 2003a and b). In contrast, an IPD3 knock-out mutation in the Medicago R108 ecotype blocks arbuscule formation similarly to Lotus cyclops mutants, which indicates that the effects on the AM interaction are also influenced by the genetic background of the plant (Horváth et al. 2011; Yano et al. 2008). In conclusion, in pea and Medicago, the DMI3-IPD3 module is essential for the accommodation of rhizobia in new organelle-like membrane compartments in analogy to the intracellular accommodation of AM fungi.

\section{MATERIALS AND METHODS}

\section{Plant lines, bacterial and fungal strains, and growth conditions.}

The M. truncatula 'Jemalong' lines J5 and A17 were used as WT reference lines. Mtsym1-1/TE7 (Bénaben et al. 1995) was crossed to $M$. truncatula accession A20 and selfed to generate a segregating F2 population. The Tnt1/Mere-transposontagged line 76A-24 (T00076A self-descent numbered 24) was identified in a collection of Tntl-tagged M. truncatula Jemalong lines generated at LIPM Toulouse (Iantcheva et al. 2009) and screened for nodulation mutant phenotypes. Phenotypic analysis was performed after two $\mathrm{BC}$ (BC2 lines). 76A-24 was crossed to Mtsym1/TE7 to show allelism. Mtsym1-1 was further crossed to TR3 (Sagan et al. 1998) to study allelism. TR3, TR9, TR13, TR62, TR69, and TRV15 were previously shown 
to be allelic (Sagan et al. 1998). M4 and F2 of BC1 seed were used for phenotypic analysis of these alleles. For analysis of nodule phenotypes, plants were grown in either perlite (Limpens et al. 2004) or aeroponic caissons (Barker et al. 2006). Sinorhizobium meliloti strain Sm2011 was used for inoculation. Additionally, Sm2011-GFP (Limpens et al. 2003), Sm2011-mRFP (Smit et al. 2005), and Sm2011 nodL::Tn5-GFP (Limpens et al. 2003) were used.

Three previously identified Pssym33 alleles were analyzed: RisFixU (genetic background Finale) (Voroshilova et al. 2001), SGEFix-2 (Tsyganov et al. 1998), and SGEFix-5, with genetic background SGE. Finale and SGE were used as respective WT references. Pea plants were inoculated with $R h i$ zobium leguminosarum bv. viciae CIAM1026 in quartz sand according to Borisov and associates (1997).

Agrobacterium rhizogenes-mediated root transformations were done according to Limpens and associates (2004) using strain MSU440 (Sonti et al. 1995). The Escherichia coli strain DH5 $\alpha$ was used for cloning and strain DB3.1 (Invitrogen, Carlsbad, CA, U.S.A.) for propagation of GATEWAY compatible vectors containing the $c c d B$ gene.

Glomus intraradices N. C. Schenck \& G. S. Sm., isolate CIAM8 (Muromtsev et al. 1989) from the Collection of the All-Russia Institute for Agricultural Microbiology (registered in the European Bank of Glomales as isolate BEG144), was used for inoculation of Medicago plants. To inoculate plants, a living culture of $G$. intraradices was obtained in an inoculation system with a nurse plant (Rosewarne et al. 1997). Allium schoenoprasum L. was used as a nurse plant, as described by Demchenko and associates (2004), except that phosphates were not included in the nutrient solution.

\section{AM phenotype analysis.}

Plants were collected at 18 and 62 days. Root fragments were collected individually from 6 to 10 plants per treatment combination. To visualize fungal structures in the root samples, ink staining was performed as described by Vierheilig and associates (1998). Roots were cut in fragments, with a total length up to $30 \mathrm{~cm}$ per plant, and mounted on glass slides in glycerol. AM development in the roots was estimated according to Trouvelot and associates (1986) using an Opton 35 (Opton, Germany, Oberkochen, Germany) light microscope for two parameters: intensity of mycorrhizal colonization in the root system (M\%) and arbuscule abundance in mycorrhizal root fragments $(\mathrm{a} \%)$. The data were compared by Student's $t$ test with the help of SigmaStat 2.3 for Windows (SPSS Inc., Chicago).

\section{Constructs.}

The inferred MtIPD3 promoter, 1,048 bp upstream of the IPD3 start codon, was PCR amplified with Phusion high-fidelity Taq polymerase (New England Biolabs, Beverly, MA, U.S.A.) from genomic DNA using primers MtIPD3pF (5'-CACCAA GCTTAAGTGGAGTCAAAAGAAATAGTTTATATG-3') and MtIPD3pR (5'-AAAGGCGCGCCGAAACACTTGAATGATG CTTGAACTTATT- $3^{\prime}$ ). The promoter fragment was cloned into pENTR-p4p1r using HindIII and AscI (underlined), resulting in pENTR4-1-MtIPD3p. Additionally, this promoter fragment was HindIII-AscI cloned into pENTR-p4p1r-MCSGFP (containing a multiple cloning site in front of eGFP to make N-terminal GFP fusions) to generate pENTR4-1MtIPD3p-GFP. The MtIPD3 cds was PCR amplified from 14day-old nodule cDNA using primers MtIPD3-F (5'-CACCA TGGAAGGGAGAGGATTTTCTGGT-3') and MtIPD-R (5'-T CAAATCTTTCCAGTTTCTGATAGA-3'). The resulting 1,546bp fragment was directionally cloned into pENTR-D-TOPO (Invitrogen), resulting in pENTR-MtIPD3. Next, a multisite GATEWAY reaction with LR Clonase II plus (Invitrogen) was performed using pENTR4-1-MtIPD3p, pENTR-MtIPD3, pENTR-p2rp3-Stop-T35S, and pKGW-RR-MGW (a modified multisite GATEWAY-compatible binary vector containing AtUbiquitin10p:DsRED1 to select transgenic roots) (Limpens et al. 2009) to generate MtIPD3p:IPD3. A multisite GATEWAY reaction using pENTR-MtIPD3, pENTR4-1-MtIPD3pGFP, pENTR-p2rp3-Stop-T35S, and pKGW-RRMGW was performed to generate MtIPD3p:GFP-MtIPD3. To construct UBQ3:GFP-IPD3, pENTR-MtIPD3 was recombined into UBQ3-pK7WGF2-RR (Limpens et al. 2009) using LR Clonase II (Invitrogen). Primers MtIPD3-F and MtIPD3-R were further used to amplify the MtIPD3 genomic fragment from Mtsym1/TE7 genomic DNA using Phusion Taq polymerase. The resulting 3,835-bp fragment was directionally cloned into pENTR-D-TOPO and subsequently recombined into UBQ3pK7WGF2-RR to generate UBQ3:GFP-IPD3tr.

For the 35S:DMI3*[1-311] construct, an enhanced Cauliflower mosaic virus (CaMV)35S promoter (ep35S) was first PCR amplified from pCAMBIA1300 using primers P35S_t (5'-GGGGGCGCGCCATGGTGGAGCACGACACTC-3') and P35S_b (5'-GGCCCGGGAGAGATAGATTTGTAGAGAGAG ACTGGTGA-3'). It was inserted into pENTR-p2rp3-MCSStop-T35S using AscI and SmaI restriction enzymes. A 933-bp DMI3 cDNA fragment was PCR amplified from A17 root cDNA using primers cMtDMI3_t (5'-GGGCCCGGGATG GGATATGGAACAAGAAAAC- $\left.3^{\prime}\right)$ and tMtDMI3_b (5'-GG GGTACCGGCTTTCTCACCTTTGACC-3') and cloned into pENTR-p2rp3-ep35S-MCS-Stop-T35s using SmaI and KpnI. Finally, it was recombined into pKGW-RR-MGW in a multiple GATEWAY reaction using Clonase II plus (Invitrogen), resulting in 35S:DMI3*[1-311].

For the 35S:CRE1*[L267F] construct, MtCRE1 was PCR amplified from $M$. truncatula genomic DNA in two parts, using the primers $5^{\prime}$-CACCATGGGTCTTCTCTTGAAGATG AA-3' and 5'-TAGGCACTTACTGATACTCAAACCA-3' for part one and 5'-CACCTTAATT-GCTGATGAAGAGTTT- $3^{\prime}$ and 5'-TCATGAATCTACTGAAGTAGGTTTTG-3' for part two. The two parts were then cloned into pENTR-D-Topo vector (Invitrogen), creating pENTR1-2_MtCRE1-part1 and pENTR12_MtCRE1-part2. The L267F mutation was introduced in pENTR1-2_MtCRE1-part1 using the QuikChange XL sitedirected mutagenesis kit (Stratagene, La Jolla, CA, U.S.A.) with primers 5'-GTCACTTGTGGAAAATTTAtTTGGTCAA CTTG-CTGGTCATC- $3^{\prime}$ and 5'-GATGACCAGCAAGTTGAC CAAaTAAATTTTCCAC-AAGTGAC-3', creating pENTR1-2 MtCRE1L267F-part $1 *$. Next, part $1 *$ and part 2 were combined by overlap PCR, using the primers $5^{\prime}$-ggggGCGGCCGCATG G-GTCTTCTCTTGAAGATGAA-3', 5'-ttgaccacccattagttcaac TAGGCACTTAC-TGATACTCAAACCA-3', 5'-GTAAGTGC CTAgttgaactaatgggtggtcaaa-3', and 5'-ggggGGCGCGCCTCA TGAATCTACTGAAGTAGGTTTTG- $3^{\prime}$, and the product was ligated using NotI and AscI (underlined) into a pENTR-D-Topo vector, creating pENTR1-2_MtCRE1L267F. The CaMV35S promoter and terminator were cloned into pENTR4-1 and pENTR2-3 (Invitrogen), thereby creating two modified pENTR clones: pENTR4-1_p35S and pENTR2-3_T35S. All three ENTR vectors were combined into the binary destination vector $\mathrm{pKGW}$-RR-MGW by a multisite gateway reaction (Invitrogen), resulting in 35S:CRE1*[L267F].

\section{Map-based cloning.}

A segregating F2 population (99 plants) of a cross between Mtsym 1/TE7 and A20 containing 23 homozygote mutants was used for mapping. All plants showing crossovers between markers $002 \mathrm{C} 10$ and $18 \mathrm{M} 20$ were phenotyped in the next generation (20 F3 plants per F2 plant) to determine the Mtsym 1 genotype of the corresponding F2 plants. DNA was extracted using 
the Qiagen DNeasy plant mini kit. The following simple-sequence repeat (or cleaved amplified polymorphic sequence [CAPS]) markers were used for mapping on Medicago Linkage Group 5; PCR products were analyzed on a 3.5\% agarose gel: MtB60, MtB146, MtB23, and MtB255 (Mun et al. 2006): 18M20, TCAGATCGACTGCAACTCCA and TGAGCACAT GATCCTTTATACTTG; 8D15, TAATTGGGGATGAAAATC TG and CCTCATGTCACTCATCATCA; 34B21, TTCAGAA AAACCCAAACCAAG and ACATGAGAGCATCCGACC CA; CU4695, TGCCACCAAAGCTAACAAACTC and TGG GTTCATCATGGACCTTTTAC; CU469(B), CCACAAAGCG TCCACCATAAAC and CAACCAAAGAAGAAGAACTCC AAACA; CU914, GTGTCATTAATGAACTTCCAACCTT and GTCCACATCAAACACATCGTAAGA; CU469, GGACCTAT GCAAATGACCTTCTACAA and CTTTAATGGCCGCAAAT CTTACTT; $81 \mathrm{G} 16$ (CAPS enzyme HindIII), CCACGCGATT TTGGGACTA and CAAAAAGCCTTATGAACCTAACCT; CU137, GAGGAAGGAGAAGGGAAAATAATC and CAAC ATAATGGGAAATCAAACAAC; CT573, TAAATGTGACC GGGGGAGTATG and GCTCATGGATTAGGAGGTGGTCA; 19c21a, AAATGGACCCTGATGATTCG and GGGGGATGG ATACTAGAGGG; 002C10, GGGAAGTTAAGCATTTCCCA and TGGTTTGTGGCATTCATTGT; 001B12, TGATCCTTTC CAAGAAGCG and CGCTAATTGCTGGCTTCAAA

The MtIPD3 gene was PCR amplified from genomic DNA of the different mutant lines and the corresponding WT reference lines using primers MtIPD3-F and MtIPD3-R and examined by sequence analysis.

Sym33 mapping was done using a F2 population (95 plants) of a cross between WT10584 (Swiecicki and Irzykowska 1998) and SGEFix-2(sym33) (Tsyganov et al. 1994). DNA was extracted using the standard cetyltrimethylammonium bromide method (Rogers and Bendich 1985). The following cross-species CAPS markers were used: Gst (restriction-enzyme TaiI) forward (F), CAA TTG AAC ACT CTT ACT CAG and reverse (R), AGA TGC AAA GCT TCC TTG CT; IPD3 (restrictionenzyme $P f e$ I) F, TGC AAA ATA CTC AAG CAC CA and R, TGT TTC CAT GAG CTA TCA CAA AG; Alat- $C$ F, CTG ACC TTC CCT CGC CAG (restriction-enzyme FspBI), and R, CCT TGC TCG CAC CAT CAG T; and Enod40 F, TGA AGG TTG TCT GGT GTC TA (WT10584-allele-specific PCR) and R, TTG AAG AAA AGA AAC AGG AAT TA.

The PsIPD3 gene was PCR amplified from genomic DNA of the mutant lines and the corresponding WT reference lines using primers PsIPD3-F (5'-ATGGAAGGGAGAGGATTTTC TG-3') and PsIPD3-R (5'-TTAAATCTTTCCAGTTTCTGATA AAAG- $3^{\prime}$ ) and examined by sequence analyses.

\section{Microscopy.}

Transgenic roots and nodules were selected based on GFP or DsRED1 expression using a Leica MZFLIII binocular fitted with HQ470/40, HQ525/50, HQ553/30, and HQ620/60 optical filters (Leica Microsystems, Rijswijk, The Netherlands). Transgenic nodules were hand sectioned using double-razor blades and mounted on microscope slides in $0.1 \mathrm{M}$ phosphate buffer, $\mathrm{pH} 7.4$, containing sucrose at $25 \mathrm{mg} / \mathrm{ml}$. Transgenic roots and sectioned nodules were further analyzed on a Zeiss LSM 510 confocal laser scanning microscope (Carl-Zeiss Axiovert [Oberkochen, Germany] $100 \mathrm{M}$ equipped with a LSM510, an argon laser with a 488-nm laser line, a helium-neon laser with a 543$\mathrm{nm}$ laser line); $488 \mathrm{~nm}$ (GFP) and $543 \mathrm{~nm}$ (DsRED1/mRFP); GFP emission was selectively detected using a 505- to 530-nm band-pass filter; DsRED1/mRFP emission was detected using a 560- to 615-nm band-pass or 560-nm long-pass filter. Infection threads phenotypes were examined using a Nikon Optiphot-2 coupled to a mercury lamp using an optical filter to detect GFP fluorescence (GFP-expressing Sm2011 strains).

\section{Quantitative RT-PCR.}

Quantitative RT-PCR was conducted on RNA isolated form 12 day-old Medicago WT nodules as well as on RNA from 12 day-old Mtsyml type 1 and type 2 nodules of plants grown in perlite (Limpens et al. 2009). Total RNA was isolated and DNAse treated using the Plant RNeasy kit (Qiagen, Basel, Switzerland) according to the manufacturer's instructions. cDNA was synthesized from $1 \mu \mathrm{g}$ of total RNA using the Taqman Gold RT-PCR kit (Perkin-Elmer Applied Biosystems) in a total volume of $50 \mu \mathrm{l}$ using random hexamer primers (10 $\mathrm{min}$ at $25^{\circ} \mathrm{C}, 30 \mathrm{~min}$ at $48^{\circ} \mathrm{C}$, and $5 \mathrm{~min}$ at $95^{\circ} \mathrm{C}$ ). Quantitative PCR reactions were performed in (technical) triplicate on $1 \mu \mathrm{l}$ of cDNA using the Quantitative PCR Core kit for SYBR Green I (Eurogentec), and real-time detection was performed on a MyiQ (Bio-Rad) (40 cycles of $95^{\circ} \mathrm{C}$ for $10 \mathrm{~s}$ and $60^{\circ} \mathrm{C}$ for 1 min) followed by a heat dissociation step (from 65 to $95^{\circ} \mathrm{C}$ ). Expression data were obtained from two independent biological repetitions. Primers were used at a final concentration of $300 \mathrm{nM}$. GAPDH was used as reference gene. qPCR primers used were MtIPD3: F, GCGCTCAAGAAAAATGGCTGA AGC and R, GCTTTAGTGATCGAACTTCCTTCTCAAGG; HAP2: F, AAACATTGGTGGCCTACAGC and R, CATGACG ATACCGTGTCCAG; NIN: F, GGGAGAAAGTCCGGGGAC AA and R, GACACACACCGATGCTCTTTGC; GAPDH: F, CTTCTGTTGCTTGATGAGGCTGAG and R, AGAAACTGT GTCTCGGCGAAATC; ERN: F, AGGTTCACAATCCAACA TTTC and R, TCAAATTCTGAAAGCTCCAAGC; EFD: F, GTCACATGGCTTCTCTTTCTCTTCA and R, CAAACCCA ACACAATTATTACCTTCAT; SYMREM: F, ACAAGAGCG TGTCGTGAGTG and R, TCGGTCAACTGAGTCCTTTGT; Flotillin-2: F, CAAGAGCTTTTCTCAGATAAGGC and R, ACTGATGGTGCCATGGGTATG; Flotillin-4: F, TGCGTCT GCTAATGCTTTCTGTG and R, CCGAAGTTGAGGCTGCC AAAG; RPG: F, AAAGGCGTTGACTCATTTGG and R, CTC ACCATTTGCCATCTGAA; and LIN: F, ATCAAGGTATGGG ACGCAAG and R, CCAATTTAGCATTGGCTGCT.

RT-PCR analysis of PSIPD3 in RisFixU and Finale was performed using RNA isolated from 3-day-old seedling roots using Trizol (Invitrogen). RNA ( $1 \mu \mathrm{g})$ was used to make cDNA using an oligo(dT) primer, followed by a PCR reaction (35 cycles) using primers PsIPD3-3 GTTAATGTGTCTAATCA GCAAC and PsIPD3-4 GGTATTTCGCACATTGAAAGGTA ATC.

\section{ACKNOWLEDGMENTS}

This study was supported by the Russian Ministry of Education and Science (governmental contract numbers 02.740.11.0276, 16.512.11.2155, and $\Pi 1304)$, the president of Russia supporting the leading scientific schools (HШ-3440.2010.4), RFBR (09-04-91054, 10-04-00961, and 1004-01146), and The Netherlands Organization for Scientific Research grants NWO-047.117.2005.006 and NWO-3184319448. We thank T. Huguet for providing the Mtsym1/TE7 mutant seed; D. Barker (LIPM) for valuable advice on the 76A project; and J. Garcia, J. Mari, and F. Poitevin (LIPM) for expert screening and molecular work.

\section{LITERATURE CITED}

Ardourel, M., Demont, N., Debellé, F., Maillet, F., de Billy, F., Promé, J. C., Dénarié, J., and Truchet, G. 1994. Rhizobium meliloti lipooligosaccharide nodulation factors: Different structural requirements for bacterial entry into target root hair cells and induction of plant symbiotic developmental responses. Plant Cell 6:1357-1374.

Arrighi, J. F., Godfroy, O., de Billy, F., Saurat, O., Jauneau, A., and Gough, C. 2008. The RPG gene of Medicago truncatula controls Rhizobium-directed polar growth during infection. Proc. Natl. Acad. Sci. U.S.A. 105:9817-9822.

Aubert, G., Morin, J., Jacquin, F., Loridon, K., Quillet, M. C., Petit, A., Rameau, C., Lejeune-Hénaut, I., Huguet, T., and Burstin, J. 2006. Functional mapping in pea, as an aid to the candidate gene selection and for 
investigating synteny with the model legume Medicago truncatula. Theor. Appl. Genet. 112:1024-1041.

Barker, D. G., Pfaff, T., Moreau, D., Groves, E. D., Ruffel, S., Lepetit, M., Whitehand, S., Maillet, F., Nair, R. M., and Journet, E. P. 2006. Growing $M$ truncatula: Choice of substrates and growth conditions In: The Medicago truncatula Handbook. U. Mathesius, E. P. Journet, and L. W. Sumner, eds. The Samuel Roberts Noble Foundation, Ardmore, OK, U.S.A.

Bénaben, V., Duc, G., Lefebvre, V., and Huguet, T. 1995. TE7, An Inefficient Symbiotic Mutant of Medicago truncatula Gaertn cv. Jemalong. Plant Physiol. 107:53-62.

Bersoult, A., Camut, S., Perhald, A., Kereszt, A., Kiss, G. B., and Cullimore, J. V. 2005. Expression of the Medicago truncatula DMI2 gene suggests roles of the symbiotic nodulation receptor kinase in nodules and during early nodule development. Mol. Plant-Microbe Interact. 18:869-876.

Borisov, A. Y., Rozov, S. M., Tsyganov, V. E., Morzhina, E. V., Lebsky, V. K., and Tikhonovich, I. 1997. Sequential functioning of Sym13 and Sym31, two genes affecting symbiosome development in root nodules of pea (Pisum sativum L). Mol. Gen. Genet. 254:592-598.

Brewin, N. J. 2004. Plant cell wall remodelling in the Rhizobium-legume symbiosis. Crit. Rev. Plant Sci. 23:293-316.

Capoen, W., and Oldroyd, G. 2008. How CYCLOPS keeps an eye on plant symbiosis. Proc. Natl. Acad. Sci. U.S.A. 105:20053-20054.

Capoen, W., Goormachtig, S., De Rycke, R., Schroeyers, K., and Holsters, M. 2005. SrSymRK, a plant receptor essential for symbiosome formation. Proc. Natl. Acad. Sci. U.S.A. 102:10369-10374.

Catoira, R., Galera, C., de Billy, F., Penmetsa, R. V., Journet, E. P., Maillet, F., Rosenberg, C., Cook, D., Gough, C., and Dénarié, J. 2000. Four genes of Medicago truncatula controlling components of a Nod factor transduction pathway. Plant Cell 12:1647-1666.

Chen, C., Ané, J. M., and Zhu, H. 2008. OsIPD3, an ortholog of the Medicago truncatula DMI3 interacting protein IPD3, is required for mycorrhizal symbiosis in rice. New Phytol. 180:311-315.

Combier, J. P., Frugier, F., de Billy, F., Boualem, A., El-Yahyaoui, F., Moreau, S., Vernié, T., Ott, T., Gamas, P., Crespi, M., and Niebel, A. 2006. MtHAP2-1 is a key transcriptional regulator of symbiotic nodule development regulated by microRNA169 in Medicago truncatula. Genes Dev. 20:3084-3088.

Demchenko, K., Winzer, T., Stougaard, J., Parniske, M., and Pawlowski, K. 2004. Distinct roles of Lotus japonicus SYMRK and SYM15 in root colonisation and arbuscule formation. New Phytol. 163:381-392.

Gleason, C., Chaudhuri, S., Yang, T., Muñoz, A., Poovaiah, B. W., and Oldroyd, G. E. 2006. Nodulation independent of rhizobia induced by a calcium-activated kinase lacking autoinhibition. Nature 441:1149-1152.

Godfroy, O., Debellé, F., Timmers, T., and Rosenberg, C. 2006. A rice calcium- and calmodulin-dependent protein kinase restores nodulation to a legume mutant. Mol. Plant-Microbe Interact. 19:495-501.

Gonzalez-Rizzo, S., Crespi, M., and Frugier, F. 2006. The Medicago truncatula CRE1 cytokinin receptor regulates lateral root development and early symbiotic interaction with Sinorhizobium meliloti. Plant Cell 18:2680-2693.

Grimsrud, P. A., den Os, D., Wenger, C. D., Swaney, D.L., Schwartz, D., Sussman, M. R., Ané, J. M., and Coon, J. J. 2010. Large-scale phosphoprotein analysis in Medicago truncatula roots provides insight into in vivo kinase activity in legumes. Plant Physiol. 152:19-28.

Haney, C. H., and Long, S. R. 2010. Plant flotillins are required for infection by nitrogen-fixing bacteria. Proc. Natl. Acad. Sci. U.S.A. 107:478483

Hayashi, T., Banba, M., Shimoda, Y., Kouchi, H., Hayashi, M., and Imaizumi-Anraku, H. 2010. A dominant function of CCaMK in intracellular accommodation of bacterial and fungal endosymbionts. Plant $\mathrm{J}$. 63:141-154.

Horváth, B., Yeun, L. H., Domonkos, A., Halász, G., Gobbato, E., Ayaydin, F., Míró, K., Hirsch, S., Sun, J., Tadege, M., Ratet, P., Mysore K., Ané, J.-M., Oldroyd, G .E. D., and Kaló, P. 2011. Medicago truncatula IPD3 is a member of the common symbiotic signaling pathway required for rhizobial and mycorrhizal symbioses. Mol. Plant-Microbe Interact. 24:1345-1358.

Iantcheva, A., Chabaud, M., Cosson, V., Barascud, M., Schutz, B., PrimardBrisset, C., Durand, P., Barker, D. G., Vlahova, M., and Ratet, P. 2009. Osmotic shock improves Tnt1 transposition frequency in Medicago truncatula $\mathrm{cv}$. Jemalong during in vitro regeneration. Plant Cell Rep. 28:1563-1572.

Jacobi, L. M., Petrova, O. S., Tsyganov, V. E., Borisov, A. Y., and Tikhonovich, I. A. 2003a. Effect of mutations in the pea genes Sym33 and Sym40. I. Arbuscular mycorrhiza formation and function. Mycorrhiza 13:3-7.

Jacobi, L. M., Zubkova, L. A., Barmicheva, E. M., Tsyganov, V. E., Borisov, A. Y., and Tikhonovich, I. A. 2003b. Effect of mutations in the pea genes Sym33 and Sym40. II. Dynamics of arbuscule development and turnover. Mycorrhiza 13:9-16.

Jones, K. M., Kobayashi, H., Davies, B. W., Taga, M. E., and Walker, G. C. 2007. How rhizobial symbionts invade plants: The SinorhizobiumMedicago model. Nat. Rev. Microbiol. 5:619-633.

Kevei, Z., Lougnon, G., Mergaert, P., Horváth, G. V., Kereszt, A., Jayaraman, D., Zaman, N., Marcel, F., Regulski, K., Kiss, G. B., Kondorosi, A., Endre, G., Kondorosi, E., and Ané, J. M. 2007. 3-Hydroxy-3-methylglutaryl coenzyme a reductase 1 interacts with NORK and is crucial for nodulation in Medicago truncatula. Plant Cell 19:3974-3989.

Kiss, E., Oláh, B., Kaló, P., Morales, M., Heckmann, A. B., Borbola, A., Lózsa, A., Kontár, K., Middleton, P., Downie, J. A., Oldroyd, G. E., and Endre, G. 2009. LIN, a novel type of U-box/WD40 protein, controls early infection by rhizobia in legumes. Plant Physiol. 151:1239-1249.

Lefebvre, B., Timmers, T., Mbengue, M., Moreau, S., Hervé, C., Tóth, K., Bittencourt-Silvestre, J., Klaus, D., Deslandes, L., Godiard, L., Murray, J. D., Udvardi, M. K., Raffaele, S., Mongrand, S., Cullimore, J., Gamas, P., Niebel, A., and Ott, T. 2010. A remorin protein interacts with symbiotic receptors and regulates bacterial infection. Proc. Natl. Acad. Sci. U.SA. 107:2343-2348.

Lévy, J., Bres, C., Geurts, R., Chalhoub, B., Kulikova, O., Duc, G., Journet, E. P., Ané, J. M., Lauber, E., Bisseling, T., Dénarié, J., Rosenberg, C., and Debellé, F. 2004. A putative Ca2+ and calmodulin-dependent protein kinase required for bacterial and fungal symbioses. Science 303:1361-1364.

Limpens, E., Franken, C., Smit, P., Willemse, J., Bisseling, T., and Geurts, R. 2003. LysM domain receptor kinases regulating rhizobial Nod factor-induced infection. Science 302:630-633.

Limpens, E., Ramos, J., Franken, C., Raz, V., Compaan, B., Franssen, H., Bisseling, T., and Geurts, R. 2004. RNA interference in Agrobacterium rhizogenes-transformed roots of Arabidopsis and Medicago truncatula. J. Exp. Bot. 55:983-992.

Limpens, E., Mirabella, R., Fedorova, E., Franken, C., Franssen, H., Bisseling, T., and Geurts, R. 2005. Formation of organelle-like N2-fixing symbiosomes in legume root nodules is controlled by DMI2. Proc. Natl. Acad. Sci. U.S.A. 102:10375-10380.

Limpens, E., Ivanov, S., van Esse, W., Voets, G., Fedorova, E., and Bisseling, T. 2009. Medicago N2-fixing symbiosomes acquire the endocytic identity marker Rab7 but delay the acquisition of vacuolar identity. Plant Cell 21:2811-2828.

Marsh, J. F., Rakocevic, A., Mitra, R. M., Brocard, L., Sun, J., Eschstruth, A., Long, S. R., Schultze, M., Ratet, P., and Oldroyd, G. E. 2007. Medicago truncatula NIN is essential for rhizobial-independent nodule organogenesis induced by autoactive calcium/calmodulin-dependent protein kinase. Plant Physiol. 144:324-335.

Maunoury, N., Redondo-Nieto, M., Bourcy, M., Van de Velde, W., Alunni, B., Laporte, P., Durand, P., Agier, N., Marisa, L., Vaubert, D., Delacroix, H., Duc, G., Ratet, P., Aggerbeck, L., Kondorosi, E., and Mergaert, P. 2010. Differentiation of symbiotic cells and endosymbionts in Medicago truncatula modulation are coupled to two transcriptome-switches. PLOS ONE 5(3):e9519. doi:10.1371/journal.pone.0009519. Published online.

Messinese, E., Mun, J. H., Yeun, L. H., Jayaraman, D., Rougé, P., Barre, A., Lougnon, G., Schornack, S., Bono, J. J., Cook, D. R., and Ané, J. M. 2007. A novel nuclear protein interacts with the symbiotic DMI3 calcium- and calmodulin-dependent protein kinase of Medicago truncatula. Mol. Plant-Microbe Interact. 20:912-921.

Middleton, P. H., Jakab, J., Penmetsa, R. V., Starker, C. G., Doll, J., Kaló, P., Prabhu, R., Marsh, J. F., Mitra, R. M., Kereszt, A,. Dudas, B. VandenBosch, K., Long, S. R., Cook, D. R., Kiss, G. B., and Oldroyd, G. E. 2007. An ERF transcription factor in Medicago truncatula that is essential for Nod factor signal transduction. Plant Cell 19:1221-1234

Mitra, R. M., Gleason, C. A., Edwards, A., Hadfield, J., Downie, J. A., Oldroyd, G. E., and Long, S. R. 2004. A Ca2+/calmodulin-dependent protein kinase required for symbiotic nodule development: Gene identification by transcript-based cloning. Proc. Natl. Acad. Sci. U.S.A. 101:4701-4705.

Morandi, D., Prado, E., Sagan, M., and Duc, G. 2005. Characterisation of new symbiotic Medicago truncatula (Gaertn) mutants, and phenotypic or genotypic complementary information on previously described mutants. Mycorrhiza 15:283-289.

Mun, J. H., Kim, D. J., Choi, H. K., Gish, J., Debellé, F., Mudge, J., Denny, R., Endré, G., Saurat, O., Dudez, A. M., Kiss, G. B., Roe, B., Young, N. D., and Cook, D. R. 2006. Distribution of microsatellites in the genome of Medicago truncatula: A resource of genetic markers that integrate genetic and physical maps. Genetics 172:2541-2555.

Muromtsev, G. S., Marshunova, G. A., and Jacobi, L. M. 1989. USSR Inventor's Certificate no.1501509.

Murray, J. D., Karas, B. J., Sato, S., Tabata, S., Amyot, L., and Szczyglowski, K. 2007. A cytokinin perception mutant colonized by 
Rhizobium in the absence of nodule organogenesis. Science 315:101104

Oldroyd, G. E., and Downie, J. A. 2008. Coordinating nodule morphogenesis with rhizobial infection in legumes. Annu. Rev. Plant Biol. 59:519-546.

Op den Camp, R., Streng, A., De Mita, S., Cao, Q., Polone, E., Liu, W., Ammiraju, J. S., Kudrna, D., Wing, R., Untergasser, A., Bisseling, T., and Geurts, R. 2010. LysM-type mycorrhizal receptor recruited for Rhizobium symbiosis in nonlegume parasponia. Science 331:909-912.

Rakocevic, A., Mondy, S., Tirichine, L., Cosson, V., Brocard, L., Iantcheva, A., Cayrel, A., Devier, B., Abu El-Heba, G. A., and Ratet, P. 2009. MERE1, a low-copy-number copia-type retroelement in Medicago truncatula active during tissue culture. Plant Physiol. 151:12501263.

Riely, B. K., Lougnon, G., Ané, J.-M., and Cook, D. R. 2007. The symbiotic ion channel homolog DMI1 is localized in the nuclear membrane of Medicago truncatula roots. Plant J. 49:208-216.

Rogers, S. O., and Bendich, A. J. 1985. Extraction of DNA from milligram amounts of fresh, herbarium and mummified plant tissues. Plant Mol. Biol. 5:69-76.

Rosewarne G., Barker, S. L., and Smith, S. E. 1997. Production of near synchronous colonisation in tomato for developmental and molecular analysis of mycorrhiza. Mycol. Res. 101:966-970.

Sagan, M., de Larembergue, H., and Morandi, D. 1998. Genetic analysis of symbiosis mutants in Medicago truncatula. Pages 317-318 in: Biological Nitrogen Fixation for the 21st Century. C. Elmerich, A. Kondorosi, and W. E. Newton, eds. Kluwer, Dordrecht, The Netherlands.

Schulze-Lefert, P. 2004. Knocking on the heaven's wall: Pathogenesis of and resistance to biotrophic fungi at the cell wall. Curr. Opin. Plant Biol. 7:377-383.

Smit, P., Raedts, J., Portyanko, V., Debellé, F., Gough, C., Bisseling, T., and Geurts, R. 2005. NSP1 of the GRAS protein family is essential for rhizobial Nod factor-induced transcription. Science 308:1789-1791.

Smit, P., Limpens, E., Geurts, R., Fedorova, E., Dolgikh, E., Gough, C., and Bisseling, T. 2007. Medicago LYK3, an entry receptor in rhizobial nodulation factor signaling. Plant Physiol. 145:183-91.

Sonti, R. V., Chiurazzi, M., Wong, D., Davies, C. S., Harlow, G. R., Mount, D. W., and Signer, E. R. 1995. Arabidopsis mutants deficient in T-DNA integration. Proc. Natl. Acad. Sci. U.S.A. 92:11786-11790.

Swiecicki, W. K., and Irzykowska, L. A. 1998. A new gene for precocious yellowing on linkage group I. Pisum Genet. 30:24.

Tirichine, L., Imaizumi-Anraku, H., Yoshida, S., Murakami, Y., Madsen, L. H., Miwa, H., Nakagawa, T., Sandal, N., Albrektsen, A. S., Kawaguchi, M., Downie, A., Sato, S., Tabata, S., Kouchi, H., Parniske, M., Kawasaki, S., and Stougaard, J. 2006. Deregulation of a Ca2+/calmodulin-dependent kinase leads to spontaneous nodule development. Nature 441:11531156.

Tirichine, L., Sandal, N., Madsen, L.H., Radutoiu, S., Albrektsen, A. S., Sato, S., Asamizu, E., Tabata, S., and Stougaard, J. 2007. A gain-offunction mutation in a cytokinin receptor triggers spontaneous root nodule organogenesis. Science 2315:104-107.

Trouvelot, A., Kough, J. L., and Gianinazzi-Pearson, V. 1986. Mesure du taux de mycorhization VA d'un système radiculaire. Recherche de méthodes d'estimation ayant une signification fonctionnelle. Pages 217 221 in: Physiological and Genetical Aspects of Mycorrhizae. V. Gianinazzi-Pearson and S. Gianinazzi, eds. INRA, Paris.

Tsyganov, V. E., Borisov, A. Y., Rozov, S. M., and Tikhonovich, I. A. 1994. New symbiotic mutants of pea obtained after mutagenesis of line SGE. Pisum Genet. 26:36-37.

Tsyganov, V. E., Morzhina, E. V., Stefanov, S. Y., Borisov, A. Y., Lebsky, V. K., and Tikhonovich, I. A. 1998. The pea (Pisum sativum L) genes sym33 and sym 40 control infection thread formation and root nodule function. Mol. Gen. Genet. 259:491-503.

Tsyganov, V. E,. Rozov, S. M., Borisov, A. Y., and Tikhonovich, I. A. 2006. Symbiotic gene SYM33 is located on linkage group I. Pisum Genet. 38:21-22.

Vasse, J., de Billy, F., Camut, S., and Truchet, G. 1990. Correlation between ultrastructural differentiation of bacteroids and nitrogen fixation in Alfalfa nodules. J. Bacteriol. 172:4295-4306.

Verma, D. P. S., and Hong, Z. 1996. Biogenesis of the peribacteroid membrane in root nodules. Trends Microbiol. 4:364-368.

Vernié, T., Moreau, S., de Billy, F., Plet, J., Combier, J. P., Rogers, C., Oldroyd, G., Frugier, F., Niebel, A., and Gamas, P. 2008. EFD is an ERF transcription factor involved in the control of nodule number and differentiation in Medicago truncatula. Plant Cell 20:2696-2713.

Vierheilig, H., Coughlan, A. P., Wyss, U., and Piche, Y. 1998. Ink and vinegar, a simple staining technique for arbuscular-mycorrhizal fungi. Appl. Environ. Microbiol. 64:5004-5007.

Voroshilova, V. A., Boesten, B., Tsyganov, V. E., Borisov, A. Y., Tikhonovich, I. A., and Priefer, U. B. 2001. Effect of mutations in Pisum sativum L genes blocking different stages of nodule development on the expression of late symbiotic genes in Rhizobium leguminosarum bv viciae. Mol. Plant-Microbe Interact. 14:471-476.

Voroshilova, V. A., Demchenko, K. N., Brewin, N. J., Borisov, A. Y., and Tikhonovich I. A. 2009. Initiation of a legume nodule with an indeterminate meristem involves proliferating host cells that harbour infection threads. New Phytol. 181:913-923.

Whitehead, L. F., and Day, D. A. 1997. The peribacteroid membrane. Physiol. Plant. 100:30-44.

Yano, K., Yoshida, S., Müller, J., Singh, S., Banba, M., Vickers, K., Markmann, K., White, C., Schuller, B., Sato, S., Asamizu, E., Tabata, S., Murooka, Y., Perry, J., Wang, T. L., Kawaguchi, M., ImaizumiAnraku, H., Hayashi, M, and Parniske, M. 2008. CYCLOPS, a mediator of symbiotic intracellular accommodation. Proc. Natl. Acad. Sci. U.S.A. 105:20540-20545.

\section{AUTHOR-RECOMMENDED INTERNET RESOURCE}

Cambia website: www.cambia.org.au 